\title{
BMJ Open Elucidating bidirectional relationship between metabolic syndrome and elevated faecal haemoglobin concentration: a Taiwanese community- based cohort study
}

\author{
Mei-Sheng Ku, ${ }^{1}$ Jean Ching-Yuan Fann, ${ }^{2}$ Sherry Yueh-Hsia Chiu, ${ }^{\odot 3,4}$ \\ Hsiu-Hsi Chen, ${ }^{5,6}$ Chen-Yang Hsu ${ }^{5}$
}

To cite: Ku M-S, Fann JC-Y, Chiu SY-H, et al. Elucidating bidirectional relationship between metabolic syndrome and elevated faecal haemoglobin concentration: a Taiwanese community-based cohort study. BMJ Open 2019;9:e021153. doi:10.1136/ bmjopen-2017-021153

- Prepublication history and additional material for this paper are available online. To view these files, please visit the journal online (http://dx.doi. org/10.1136/bmjopen-2017021153).

Received 13 December 2017 Revised 17 December 2018 Accepted 28 December 2018

Check for updates

(C) Author(s) (or their employer(s)) 2019. Re-use permitted under CC BY-NC. No commercial re-use. See rights and permissions. Published by BMJ.

For numbered affiliations see end of article.

Correspondence to Dr Chen-Yang Hsu; bacilli65@gmail.com

\section{ABSTRACT}

Objectives To elucidate the bidirectional temporal relationship between elevated faecal haemoglobin (f-Hb) concentration and metabolic syndrome (MetS).

Design A longitudinal cohort study was conducted by utilising data on community-based periodical screening for colorectal cancer with faecal immunochemical test (FIT) and health check-up for MetS.

Setting Population-based organised integrated service screening in Keelung city, Taiwan.

Participants We enrolled a total of 62,293 community residents aged $40-79$ years.

Main outcomes and measures Bidirectional outcomes of FIT-positive and MetS were measured.

Results The presence of MetS at baseline led to a statistically significant $31 \%$ elevated risk of being incident FIT-positive (adjusted HR, (aHR) $=1.31,95 \% \mathrm{Cl}: 1.14$ to 1.51) whereas the effect of those with FIT-positive at baseline on incident MetS was not statistically significant (aHR=1.06, 95\% Cl: 0.89 to 1.25) after adjusting for relevant confounders. Such an effect was particularly noted for three individual components (abnormal waist circumference, higher fasting plasma glucose and lower high-density lipoprotein).

Conclusions Our finding on the presence of MetS before FIT-positive based on bidirectional relationship assessment suggests the control of MetS may contribute to reducing the risk of colorectal neoplasia through the early surveillance of $\mathrm{f}-\mathrm{Hb}$. However, such a temporal epidemiological finding still needs to be verified by using other external data.

\section{INTRODUCTION}

While faecal immunological test (FIT) has been widely used worldwide to demonstrate a significant mortality reduction of colorectal cancer, ${ }^{1-3}$ additional values of faecal haemoglobin (f-Hb) concentration derived from FIT for predicting the risk of colorectal neoplasia and also its mortality have been corroborated in a dose-response manner in several previous studies. ${ }^{4-10}$ Such a favourable
Strengths and limitations of this study

- This is a prospective cohort study elucidating bidirectional relationships regarding the effect of both faecal immunochemical test (FIT) and metabolic syndrome (MeTS) status collected at baseline since 2001 on the incident outcome of each counterpart following over time until 2009.

- This is the first study disentangling the temporal sequence between MetS and FIT-positive that is very informative to design and plan appropriate primary prevention programme of colorectal neoplasia.

- Other unmeasured confounding factors, such as aspirin intakes, family history of colorectal cancer and the amount of physical activities should be taken into account in future studies.

- Other longitudinal cohort studies are required to verify these epidemiological associations.

predictive validity for colorectal neoplasia with $\mathrm{f}-\mathrm{Hb}$ raised the possibility of using $\mathrm{f}-\mathrm{Hb}$ as a quantitative surrogate biomarker for early prediction of colorectal neoplasia so as to dispense with the use of a longitudinal follow-up study for ascertaining colorectal neoplasia.

Better use of information on $\mathrm{f}-\mathrm{Hb}$ may also be useful for elucidating bidirectional relationship between elevated $\mathrm{f}-\mathrm{Hb}$ and metabolic syndrome (MetS), an emerging risk factor responsible for the risk of colorectal neoplasia that has been supported by epidemiological findings, ${ }^{11-14}$ molecular studies on obesity that predisposes to the development of insulin resistance via immunological pathway ${ }^{15-18}$ and others supporting the significant relationship between inflammation and tumorigenesis. ${ }^{19} 20$

From the viewpoint of primary prevention of colorectal neoplasia, clarifying the 


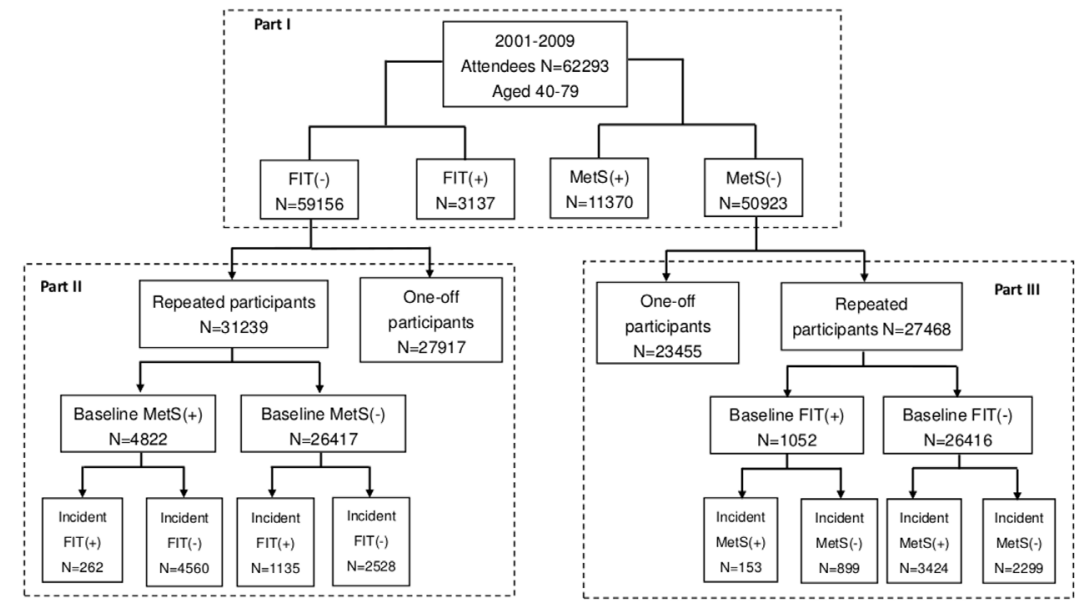

Figure 1 The flow chart for bidirectional prospective normal cohort study design (free of metabolic syndrome (MetS) or faecal immunological test (FIT) (+)). MetS, metabolic syndrome; FIT, Faecal immunological test.

temporal relationship between high $\mathrm{f}-\mathrm{Hb}$ and metabolic syndrome would provide an insight into appropriate early primary prevention programmes. Lifestyle modification for the adequate control of those biomarkers in relation to MetS would be prioritised if MetS precedes the elevated $\mathrm{f}-\mathrm{Hb}$. On the other hand, if the reverse temporal relationship is demonstrated, how to reduce the level of $\mathrm{f}-\mathrm{Hb}$ through the possible improvement of serum haemoglobin level ${ }^{21}$ may need to be considered.

We thus aimed to elucidate the bidirectional temporal relationship between high $\mathrm{f}-\mathrm{Hb}$ and MetS utilising data on a population-based periodical screening for colorectal cancer with FIT and also health check-up for MetS.

\section{METHODS}

\section{Study design}

The flowchart of study framework is diagrammed in figure 1, which consists of three main parts based on the outcome of incident FIT-positive or incident MetS. In part I, a cross-sectional analysis was conducted to investigate the relationship between prevalent (first screen) FIT-positive and MetS. We further conducted a longitudinal cohort study containing part II and part III for elucidating the bidirectional relationship between FIT and MetS. Notably, only those with negative-FIT or non-MetS who underwent repeated screening were included in the long-term follow-up study in part II and part III.

The long-term follow-up of FIT-negative (part II in figure 1) and MetS-free (part III in figure 1) cohorts enables us to elucidate the bidirectional temporal relationship between the two factors. Considering FIT-positive as dependent variable and MetS status as an independent variable, the cohort of FIT-negative subjects with longterm follow-up and ascertainment of subsequent FIT-positive results was analysed (part II, figure 1). Regarding the study using incident MetS as dependent variable and FIT status as an independent variable, the MetS-free cohort was followed over time to ascertain incident MetS (part III, figure 1).

\section{Study population and screening data collection}

The Keelung Community Integrated Screening (KCIS) programme, which provided chronic diseases and neoplasia screening simultaneously, facilitated the elucidation of the temporal sequence between MetS and elevated $\mathrm{f}-\mathrm{Hb}$ concentration after considering the demographic and lifestyle factors. Our study subjects were derived from a cohort invited to the KCIS programme for colorectal neoplasia service screening. The KCIS programme comprised multiple screening strategies, including five types of non-neoplastic diseases (including diabetes, hypertension, hyperlipidaemia, obesity, periodontal disease) and five types of neoplastic diseases (oral, cervical, breast, colorectal, liver cancers). The service of screening for multiple diseases along with the referral of attendees with positive results for confirmatory diagnosis was provided in an organised and integrated manner. ${ }^{11}$

The screening population was composed of residents aged 40-79 years who had been screened annually until 2008 and then biennially since then. Only those free of colorectal cancer were eligible for attending the screening programme. In addition, we excluded those who was prevalent cases of positive FIT test result (part II, figure 1) or MetS (part III, figure 1) depending on which is the main outcome of interest in our bidirectional study design in order to elucidate the temporal sequence of the two phenotypes. Only those with negative-FIT or non-MetS who underwent repeated screening were included in the long-term follow-up study. This cohort was followed up from the time when $\mathrm{f}-\mathrm{Hb}$ information was available in 2001 until the end of 2009 or the occurrence of colorectal cancer (CRC) or death, whichever came first. Both death and CRC were considered as censored event. Apart from information on $\mathrm{f}-\mathrm{Hb}$ concentration, we also documented individual components of MetS, including waist circumference, weight, height, blood pressure and other biochemistry index such as fasting glucose, triglyceride and high-density lipoprotein cholesterol. In addition, the baseline information relevant to MetS or FIT (including 
educational levels and dietary habits of fruits, vegetable and meat intake) were collected by questionnaires. The dietary habits considering the amount of daily consumption of fruit, vegetable and meat intake were categorised into three levels (none, 1-2 unit, and $>=3$ unit). Food modes and standard dishes or containers of each food were displayed as the portion sizes to assist the estimation of the volume of daily consumption. Individual informed consents were obtained before screening.

\section{Faecal immunochemical test measurement}

In our colorectal cancer screening programme, $\mathrm{f}-\mathrm{Hb}$ concentration measurement was based on OC-SENSOR method (Eiken Chemical Company, Tokyo, Japan), a ubiquitous method for quantitatively measuring $\mathrm{f}-\mathrm{Hb}$. Details of the procedure have been described elsewhere. ${ }^{5}$ A standard single faecal sample with $10 \mathrm{mg}$ per specimen collection device was collected and preserved in $2 \mathrm{~mL}$ buffer by trained nurses following the standard procedures. Collected samples were stored at room temperature $\left(23^{\circ} \mathrm{C}-26^{\circ} \mathrm{C}\right)$ and were sent to the community health centre in 3 days. They were then refrigerated at $4^{\circ} \mathrm{C}$. All samples were further sent to the central laboratory for analysis within 7 days of screening. The quantitative values of $\mathrm{f}-\mathrm{Hb}$ results were recorded with the unit of $\mathrm{ng}$ $\mathrm{Hb} / \mathrm{mL}(5 \mathrm{ng} \mathrm{Hb} / \mathrm{mL}=1 \mu \mathrm{g} \mathrm{Hb} / \mathrm{g}$ faeces$)$. The cut-off for identifying subjects requiring further colonoscopy examination was $100 \mathrm{ng} \mathrm{Hb} / \mathrm{mL}$. As a result, subjects with $\mathrm{f}-\mathrm{Hb}$ concentrations above $100 \mathrm{ng} \mathrm{Hb} / \mathrm{mL}$ were considered as FIT-positive.

\section{Measurement of MetS and its components}

Metabolic syndrome (MetS) was defined according to the International Diabetes Federation Consensus criteria ${ }^{22}$ from which the presence of at least three of the following criteria was derived: central obesity (waist circumference $\geq 80 \mathrm{~cm}$ for female, and $\geq 90 \mathrm{~cm}$ for male), hypertriglyceride (triglyceride $\geq 150 \mathrm{mg} / \mathrm{dL}$ ), a low level of high-density lipoprotein cholesterol (HDL-C) (HDL-C $<50 \mathrm{mg} / \mathrm{dL}$ for women and $<40 \mathrm{mg} / \mathrm{dL}$ for men), an elevated blood pressure (systolic blood pressure $\geq 130 \mathrm{~mm}$ $\mathrm{Hg}$ or diastolic blood pressure $\geq 85 \mathrm{~mm} \mathrm{Hg}$ ) and hyperglycaemia (fasting glucose $\geq 100 \mathrm{mg} / \mathrm{dL}$ ).

\section{Statistical analysis}

For descriptive analysis, we reported the percentage for positive-FIT result by different characteristics including demographic features, lifestyle factors, dietary habits and individual components of MetS. A post-hoc analysis was performed by comparing at least three levels of categorical variables as indicated in table 1 using Bonferroni correction. Regarding the part of cross-sectional study (part I, figure 1), a logistic regression analysis was applied to investigating the association between prevalent MetS status and $\mathrm{f}-\mathrm{Hb}$ concentration, with the dependent variable defined by a binary outcome, such as $\mathrm{f}-\mathrm{Hb} \geq 100$ (positive FIT result) and $<100 \mathrm{ng} \mathrm{Hb} / \mathrm{mL}$ (negative FIT result). The multiple-variable analysis was also carried out to adjust for confounding factors including age, gender, educational levels, cigarette smoking, alcohol drinking and intake of vegetable, fruit and meat. The results were presented by crude OR or adjusted OR.

We further used Cox proportional hazards regression model with the time scale of month for subjects with negative $\mathrm{f}-\mathrm{Hb}$ result or non-MetS status and the interval from the time of entry to screen until the occurrence of bidirectional outcomes of MetS and FIT-positive. Recall that while assessing bidirectional relationship, the temporal relationship between MetS status (including score and 5 components of MetS) and the occurrence of FIT-positive followed the study design in figure 1 as mentioned above.

The multinomial logistic regression was also used to evaluate the effects of baseline MetS on quartiles of $\mathrm{f}-\mathrm{Hb}$ measures (Q1: first quartile, Q2: second quartile (median), Q3: third quartile) in subsequent screen, and to examine the trend effect of MetS on f-Hb levels.

Given the assumption of constant incidence rate, Poisson regression model was applied to estimating the adjusted cumulative incidence of FIT-positive by baseline MetS status and also the cumulative incidence of MetS by the presence of FIT-positive.

\section{Patient and public involvement}

The patient and public involvement in this study was achieved by the inclusion of the personnel in the local public health sector and Public Health Bureau in Keelung City responsible for the monitoring of the heath indicators including MetS and FIT-positive. They also responsible for the consultation and provision of screening service in the communities of Keelung City. Our study subjects were enrolled through the community-based screening programme.

The results of this study will be disseminated to the public in community through the personnel of the Public Health Bureau of Keelung City.

\section{RESULTS}

A total of 62293 subjects aged 40-79 years were enrolled in this study from 2001 to 2009. Among them, 3137 were detected with FIT-positive given the criterion that $\mathrm{f}-\mathrm{Hb}$ was greater than 100. The overall positive rate of FIT was $5.0 \%$. Table 1 shows the distribution of positive rates by demographic characteristics (age, gender, educational levels and marital status), lifestyle factors (cigarette smoking, alcohol drinking, and intakes of vegetable, fruit and meat) and metabolic syndrome. Positive rate increased with age and was higher in men than women (table 1). The level of education was inversely associated with the positive rate of FIT. The widowed/divorced had also higher positive rate compared with the married/ single. As far as lifestyle factors are concerned, current smoker $(6.4 \%)$, ever drinker $(6.4 \%)$, low vegetable intake $(5.9 \%)$ and high fruit consumption $(5.6 \%)$ exhibited higher positive rate compared with the counterpart of each factor. The elevated positive rates of $6.4 \%, 5.8 \%$, 
Open access

Table 1 The distribution of FIT-positive result by demographic and lifestyle factors

\begin{tabular}{|c|c|c|c|c|}
\hline Characteristic & $\mathrm{f}-\mathrm{Hb} \geq 100(\mathrm{ng} / \mathrm{mL}) /$ Total $(\mathrm{n})$ & Positive rate (\%) & $\begin{array}{l}\text { Overall } \\
p \text { value }\end{array}$ & P value (Post-hoc)* \\
\hline Age (year) & & & $<0.0001$ & \\
\hline $40-49$ & $902 / 24410$ & 3.7 & & - \\
\hline $50-59$ & 725/17616 & 4.1 & & - \\
\hline $60-69$ & $805 / 12607$ & 6.4 & & - \\
\hline $70-79$ & $705 / 7660$ & 9.2 & & - \\
\hline Total & $3137 / 62293$ & 5.0 & & \\
\hline Gender & & & $<0.0001$ & \\
\hline Female & $1665 / 37637$ & 4.4 & & - \\
\hline Male & $1472 / 24656$ & 6.0 & & - \\
\hline Education level & & & $<0.0001$ & \\
\hline Elementary/lliterate (1) & $1577 / 25677$ & 6.1 & & - \\
\hline Junior/Seniorhigh (2) & $1187 / 27174$ & 4.4 & & (2) vs $(1),<0.0001$ \\
\hline University/Graduate (3) & $373 / 9422$ & 4.0 & & (3) vs $(1),<0.0001$ \\
\hline Marital Status & & & $<0.0001$ & \\
\hline Widowed/Divorced & $597 / 10062$ & 5.9 & & - \\
\hline Married & $2400 / 49713$ & 4.8 & & $\begin{array}{l}\text { Married vs Widowed/ } \\
\text { Divorced, }<0.0001\end{array}$ \\
\hline Single & $140 / 2515$ & 5.6 & & NS \\
\hline Cigarette smoking & & & $<0.0001$ & \\
\hline Non-smoker & $2105 / 45235$ & 4.7 & & - \\
\hline Ex-smoker & $223 / 4353$ & 5.1 & & $\begin{array}{l}\text { Ex-smoker vs Non-smokers, } \\
0.0062\end{array}$ \\
\hline Current smoker & $775 / 12062$ & 6.4 & & $\begin{array}{l}\text { Current smoker vs Non- } \\
\text { smokers, }<0.0001\end{array}$ \\
\hline Alcohol drinking & & & $<0.0001$ & \\
\hline Non-drinker & $2247 / 46948$ & 4.8 & & $\begin{array}{l}\text { Non-drinker vs Current } \\
\text { drinker, }<0.0001\end{array}$ \\
\hline Ex-drinker & $156 / 2420$ & 6.4 & & $\begin{array}{l}\text { Ex-drinker vs Current drinker, } \\
0.0006\end{array}$ \\
\hline Current drinker & $691 / 11969$ & 5.8 & & - \\
\hline Intake of vegetable & & & 0.0486 & \\
\hline Low & $65 / 1106$ & 5.9 & & NS \\
\hline Medium & $2455 / 48433$ & 5.1 & & NS \\
\hline High & $500 / 10754$ & 4.6 & & NS \\
\hline Intake of fruit & & & 0.0076 & \\
\hline Low & $882 / 18386$ & 4.8 & & Low vs High, 0.0048 \\
\hline Medium & $1395 / 28400$ & 4.9 & & Medium vs High, 0.0104 \\
\hline High & $720 / 12864$ & 5.6 & & - \\
\hline Intake of meat & & & 0.1587 & \\
\hline Low (1) & $684 / 12791$ & 5.3 & & NS \\
\hline Medium (2) & $2179 / 44266$ & 4.9 & & NS \\
\hline High (3) & $148 / 2976$ & 5.0 & & NS \\
\hline Metabolic syndrome & & & $<0.0001$ & \\
\hline Non-MetS & $2404 / 50922$ & 4.7 & & - \\
\hline MetS (Score $>=3$ ) & $733 / 11371$ & 6.4 & & - \\
\hline Waist circumference $(\mathrm{cm}) \dagger$ & & & $<0.0001$ & \\
\hline Normal & $1836 / 39963$ & 4.6 & & - \\
\hline Abnormal & $1271 / 21745$ & 5.8 & & - \\
\hline
\end{tabular}

Continued 
Table 1 Continued

\begin{tabular}{|c|c|c|c|c|}
\hline Characteristic & $\mathrm{f}-\mathrm{Hb} \geq 100(\mathrm{ng} / \mathrm{mL}) /$ Total $(\mathrm{n})$ & Positive rate $(\%)$ & $\begin{array}{l}\text { Overall } \\
\text { p value }\end{array}$ & P value (Post-hoc)* \\
\hline Blood pressureł & & & $<0.0001$ & \\
\hline Abnormal & $690 / 10970$ & 6.3 & & - \\
\hline AC Sugar(mg/dL)§ & & & $<0.0001$ & \\
\hline Triglycerides(mg/dL)ף & & & $<0.0001$ & \\
\hline Normal & $2063 / 43578$ & 4.7 & & - \\
\hline Abnormal & $1050 / 18357$ & 5.7 & & - \\
\hline $\mathrm{HDL}-\mathrm{C}(\mathrm{mg} / \mathrm{dL})^{\star *}$ & & & $<0.0001$ & \\
\hline
\end{tabular}

*Post-hoc test for groups using Bonferroni correction, only significant comparisons were listed. †Waist circumference: Abnormal: $\geq 90 \mathrm{~cm}$ (men) or $\geq 80 \mathrm{~cm}$ (women), Normal: $<90 \mathrm{~cm}$ (men) or $<80 \mathrm{~cm}$ (women). łBlood pressure: Abnormal: SBP $\geq 130(\mathrm{~mm} \mathrm{Hg})$ or DBP $\geq 85(\mathrm{~mm} \mathrm{Hg})$ or Hypertension history, Normal: SBP $<130$ (mm Hg) and DBP $<85$ (mm $\mathrm{Hg})$.

§AC Sugar (fasting plasma glucose, FPG): Abnormal: FPG $\geq 100(\mathrm{mg} / \mathrm{dL}$ ) or DM history, Normal: FPG $<100(\mathrm{mg} / \mathrm{dL})$.

१Triglycerides: Abnormal: $\geq 150$ (mg/dL), Normal: $<150$ (mg/dl).

${ }^{* *}$ HDL-C: Abnormal: $<40$ (mg/dL), Normal: $\geq 40$ (mg/dL).

$\mathrm{f}-\mathrm{Hb}$, faecal haemoglobin ; FIT, faecal immunisation test; MetS, metabolic syndrome.

$6.3 \%, 6.1 \%, 5.7 \%$ and $5.8 \%$ were noted in those with MetS, abnormal waist, elevated blood pressure, pre-diabetes/diabetes mellitus, triglyceride $>=150 \mathrm{mg} / \mathrm{dL}$ and lowered HDL-C, respectively (table 1 ).

The significant results of post-hoc analysis are also listed in table 1. As far as the variable 'Intake of fruit' is concerned, there was a significant difference in FIT positive rates between low vs high $(\mathrm{p}=0.0048)$ and medium vs high $(p=0.0104)$. Significant differences in the FIT-positive rate between non-drinker vs current drinker $(\mathrm{p}<0.0001)$ and ex-drinker and current drinker $(p=0.0006)$ were noted. There were significant differences in ex-smoker vs non-smoker $(\mathrm{p}=0.0062)$ and current smoker vs non-smoker $(p<0.0001)$. Significant comparisons in post-hoc analysis are also listed for levels of education and marital status.

\section{MetS and Prevalent FIT-positive}

Online supplementary table 1 shows the crude and adjusted odds ratios for FIT-positive in association with MetS by using binary categorisation (Yes vs No), score, and each of the five individual components for MetS. In univariate analysis, those with MetS led to a $40 \%$ $(\mathrm{OR}=1.40,95 \% \mathrm{CI}, 1.28-1.52 ; \mathrm{p}<0.0001)$ increased risk of being FIT-positive compared with those free of MetS. The similar results were also observed for a $16 \%$ incremental risk per score and $23 \%-35 \%$ elevated risk for various five individual components of MetS.

The significant elevated risk persisted after adjusting for potential confounding factors such as age, gender, education, alcohol drinking, cigarette smoking and fruit consumption for the presence of MetS $(\mathrm{aOR}=1.19,95 \%$
$\mathrm{CI}=1.08-1.30 ; \mathrm{P}=0.0002)$ and $\mathrm{MetS}$ score $(\mathrm{aOR}=1.08,95 \%$ $\mathrm{CI}=1.05$ to $1.12 ; \mathrm{p}<0.0001)$. Among the five individual components of MetS, higher fasting plasma glucose $(\mathrm{aOR}=1.09,95 \% \mathrm{CI}=1.00-1.19 ; \mathrm{p}=0.04)$ and lower HDL-C $(\mathrm{aOR}=1.21,95 \% \mathrm{CI} 1.10$ to $1.32, \mathrm{p}=0.0002)$ increased the odds of yielding FIT-positive. Considering the severity of MetS in terms of total score, we found a significant trend in association with the risk of FIT-positive (online supplementary figure $1 \mathrm{a}, \mathrm{p}<0.0001$ in trend test).

\section{Effect of baseline MetS on incident FIT-positive}

In part II analysis as shown in figure 1, there were 31239 subjects who attended subsequent colorectal cancer screen. We used the Cox proportional hazards regression model to assess the effect of baseline MetS on positive FIT result among subjects with the negative result of FIT at first screen. Table 2 shows the results of the association between baseline MetS and subsequent incident FIT-positive. The presence of MetS increased the risk of yielding incident FIT-positive in univariate analysis (HR $=1.58,95 \% \mathrm{CI}=1.38$ to $1.81 ; \mathrm{p}<0.0001)$ and multi-variable regression analysis $(\mathrm{aHR}=1.31,95 \% \mathrm{CI}=1.14$ to 1.51 ; $\mathrm{p}=0.0001$ ), after adjusting for potential confounding factors. Abnormal waist circumference $(\mathrm{aHR}=1.27,95 \%$ $\mathrm{CI}=1.13$ to $1.43 ; \mathrm{p}<0.0001$ ), higher fasting plasma glucose $(\mathrm{aHR}=1.13,95 \% \mathrm{CI}=1.00$ to $1.29 ; \mathrm{p}=0.0547)$ and lower HDL-C $(\mathrm{aHR}=1.27,95 \% \mathrm{CI}=1.09$ to $1.47 ; \mathrm{p}<0.0001)$ were those significant individual components contributing to the effect of MetS on incident FIT-positive.

In addition to incident positive FIT results, the effects of baseline MetS on the quartile of $\mathrm{f}-\mathrm{Hb}$ measures with multi-nomial logistic regression are listed in 
Open access

Table 2 Crude and adjusted HRs (aHR) for incident FIT-positive result associated with baseline metabolic syndrome

\section{f-Hb positive $(\geq 100 \mathrm{ng} / \mathrm{mL})$}

\begin{tabular}{|c|c|c|c|c|}
\hline Variable & HR & $95 \% \mathrm{CI}$ & aHR & $(95 \% \mathrm{Cl})$ \\
\hline \multicolumn{5}{|l|}{ Metabolic syndrome } \\
\hline Yes vs no & 1.58 & (1.38 to 1.81$)$ & 1.31 & (1.14 to 1.51$)$ \\
\hline Score $=1$ vs Score $=0$ & 1.24 & (1.08 to 1.42$)$ & 1.09 & (0.94 to 1.25$)$ \\
\hline Score $=2$ vs Score $=0$ & 1.60 & (1.38 to 1.85$)$ & 1.30 & (1.11 to 1.51$)$ \\
\hline Score $=5$ vs Score $=0$ & 2.43 & (1.50 to 3.95$)$ & 1.88 & (1.16 to 3.07$)$ \\
\hline \multicolumn{5}{|l|}{ Individual components } \\
\hline \multicolumn{5}{|l|}{ Waist circumference $(\mathrm{cm})^{\star}$} \\
\hline Abnormal vs Normal & 1.52 & (1.37 to 1.70$)$ & 1.27 & (1.13 to 1.43 ) \\
\hline \multicolumn{5}{|l|}{ High blood pressure $†$} \\
\hline Abnormal vs Normal & 1.42 & (1.26 to 1.59$)$ & 1.13 & (1.00 to 1.29$)$ \\
\hline \multicolumn{5}{|l|}{ Triglycerides (mg/dL)§ } \\
\hline Abnormal vs Normal & 1.34 & (1.20 to 1.50$)$ & 1.07 & (0.94 to 1.21$)$ \\
\hline \multicolumn{5}{|l|}{ HDL-C (mg/dL)ף } \\
\hline Abnormal vs Normal & 1.33 & (1.16 to 1.52$)$ & 1.27 & (1.09 to 1.47$)$ \\
\hline \multicolumn{5}{|l|}{ Confounders } \\
\hline \multicolumn{5}{|l|}{ Age (year) } \\
\hline $50-59$ vs $40-49$ & 1.14 & (0.98 to 1.31$)$ & 1.09 & (0.93 to 1.27$)$ \\
\hline $60-69$ vs $40-49$ & 1.80 & (1.57 to 2.07 ) & 1.61 & (1.37 to 1.89$)$ \\
\hline $\begin{array}{l}\text { University/Graduate vs } \\
\text { Elementary/Illiterate }\end{array}$ & 1.49 & (1.25 to 1.78$)$ & 1.29 & (1.09 to 1.51$)$ \\
\hline \multicolumn{5}{|l|}{ Drinking status } \\
\hline Ex-drinker vs Non-drinker & 1.40 & (1.08 to 1.81$)$ & 1.04 & (0.79 to 1.38$)$ \\
\hline Current drinker vs Non-drinker & 1.21 & (1.06 to 1.38$)$ & 0.97 & (0.84 to 1.14$)$ \\
\hline \multicolumn{5}{|l|}{ Smoking } \\
\hline Ex-smoker vs Non-smoker & 1.31 & (1.07 to 1.60$)$ & 1.06 & (0.84 to 1.34$)$ \\
\hline Current smoker vs Non-smoker & 1.62 & (1.43 to 1.85$)$ & 1.29 & (1.09 to 1.51$)$ \\
\hline Vegetable intake & 0.72 & (0.64 to 0.81$)$ & 0.74 & (0.66 to 0.83 ) \\
\hline Meat intake & 1.08 & (0.98 to 1.19$)$ & - & \\
\hline Fruit intake & 0.97 & (0.89 to 1.05$)$ & - & \\
\hline
\end{tabular}

*Waist circumference: Abnormal: $\geq 90 \mathrm{~cm}$ (male) or $\geq 80 \mathrm{~cm}$ (female), Normal: $<90 \mathrm{~cm}$ (male) or $<80 \mathrm{~cm}$ (female).

†Blood pressure: Abnormal: SBP $\geq 130(\mathrm{~mm} \mathrm{Hg})$ or DBP $\geq 85(\mathrm{~mm} \mathrm{Hg})$ or Hypertension history, Normal: SBP $<130$ ( $\mathrm{mm} \mathrm{Hg})$ and DBP $<85(\mathrm{~mm} \mathrm{Hg})$.

ҒAC Sugar(fasting plasma glucose, FPG): Abnormal: FPG $\geq 100(\mathrm{mg} / \mathrm{dL})$ or diabetes mellitus history, Normal: $\mathrm{FPG}<100(\mathrm{mg} / \mathrm{dL})$.

§Triglycerides: Abnormal: triglycerides $\geq 150$ (mg/dL), Normal: triglycerides $<150$ (mg/dL).

ПHDL-C: Abnormal: $<40$ (mg/dL), Normal: $\geq 40$ (mg/dL).

$\mathrm{f}-\mathrm{Hb}$, faecal haemoglobin ; FIT, faecal immunisation test. 


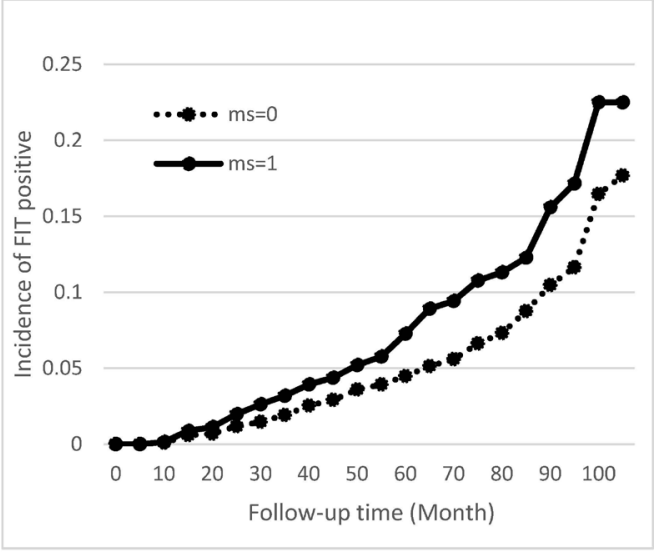

A Cumulative incidence of FIT positive results by baseline MetS status

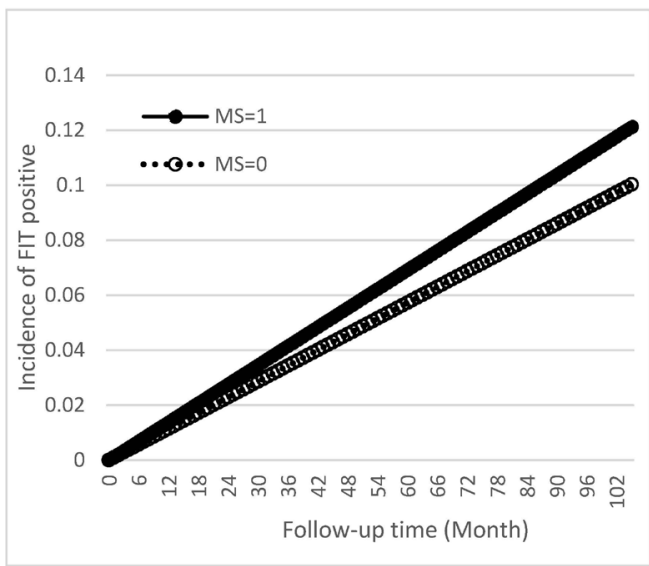

\section{Adjusted cumulative incidence of FIT positive results by baseline MetS status}

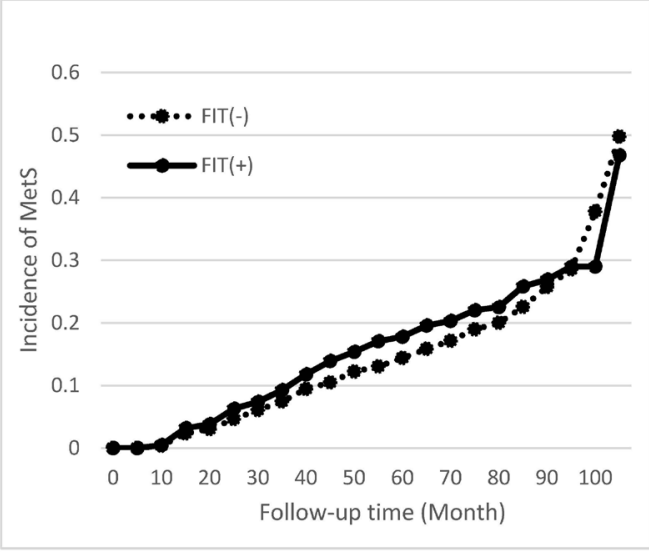

B Cumulative incidence of MetS by baseline FIT results

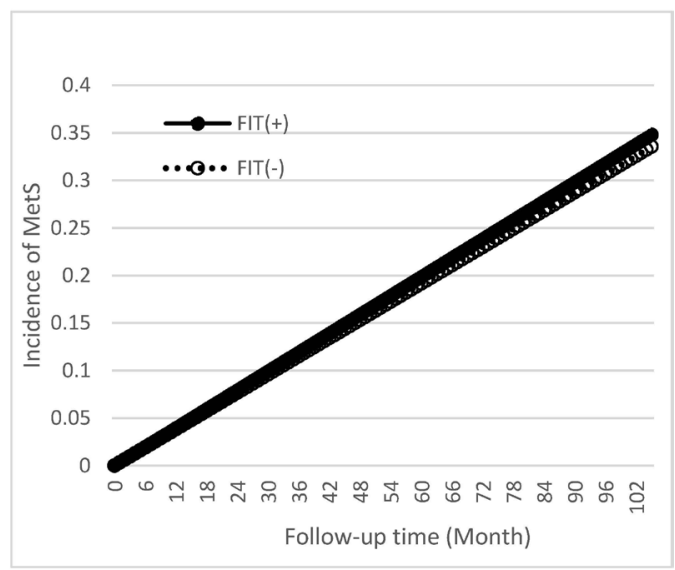

\section{Adjusted cumulative incidence of MetS} by baseline FIT results

Abbreviations: MetS: metabolic syndrome; FIT: faecal immunological test

Figure 2 Observed $(A, B)$ and predicted $(C, D)$ cumulative incidnce for FIT-positive (A, C) and MetS (B, D).

online supplementary table 2 and online supplementary figure $1 \mathrm{~b}$. Crude effect of baseline MetS on quartile of $\mathrm{f}-\mathrm{Hb}$ measures reached statistical significance (trend test, $\mathrm{p}<0.0001$ ). After adjusting for confounding factors such as age, gender, education level, smoking and drinking status, the impact of baseline MetS on higher quartile groups of $\mathrm{f}-\mathrm{Hb}$ was statistically significant (trend test, $\mathrm{p}<0.0001)$, with the order of aOR being $0.98(95 \%$ $\mathrm{CI}=0.88$ to $1.08 ; \mathrm{p}=0.6391)$ for $\mathrm{Q} 1-\mathrm{Q} 2$ group, $1.06(95 \%$ $\mathrm{CI}=0.96$ to $1.17 ; \mathrm{p}=0.2322)$ for $\mathrm{Q} 2-\mathrm{Q} 3$ group and 1.26 $(95 \% \mathrm{CI}=1.14$ to 1.38 ; $\mathrm{p}<0.0001)$ for $>\mathrm{Q} 3$ group.

\section{Effect of baseline FIT on incident metabolic status}

Among 27468 subjects free of MetS at baseline (figure 1, part III), those with FIT-positive at first screen were not statistically significantly at increased risk for incident MetS after adjusting for age, gender and other potential confounders $(\mathrm{aHR}=1.06,95 \% \mathrm{CI}=0.89,1.25 ; \mathrm{p}=0.5248)$ although a statistically significant effect was noted in univariate analysis $(\mathrm{HR}=1.19,95 \% \quad \mathrm{CI}=1.01$ to 1.40 ; $\mathrm{p}=0.0335$ ) as shown in online supplementary table 3 .
Figure 2A and B shows cumulative incidences of MetS and FIT-positive by follow-up time according to the baseline conditions. The adjusted cumulative incidences are also plotted in Figure 2C and D, with the covariates adjusted according to the corresponding model presented in table 2 and online supplementary table 3. We found that baseline MetS status had a higher risk of giving subsequent FIT-positive results whereas the baseline FIT result was not correlated with incident MetS.

\section{DISCUSSION}

The main rationale for envisaging this study is based on two streams of previous findings: (i) a significant association between MetS and colorectal neoplasia ${ }^{12}$ 23-26 and (ii) also the role of $\mathrm{f}-\mathrm{Hb}$ concentration as a predictor colorectal neoplasia and colorectal cancer mortality in a dose-response manner. ${ }^{5-7}$ By using colorectal cancer screening with FIT, colorectal cancers could be ascertained from those whose $\mathrm{f}-\mathrm{Hb}$ concentrations above 
$100 \mathrm{ng} \mathrm{Hb} / \mathrm{mL}$, FIT-positive, that are further referred to undergo colonoscopy. ${ }^{45-9}$ It is of great interest to elucidate the temporal relationship between the emerging two markers (such as MetS and $\mathrm{f}-\mathrm{Hb}$ ), which has been never addressed.

The main contribution of this study is to use a bidirectional study design to elucidate the temporal sequence between MetS and f-Hb. We first demonstrated a statistically significant association between both phenotypes by information collected at baseline followed by the application of two normal incident cohort design (free of each outcome at baseline). We found the effect of MetS on FIT-positive was statistically significant but the opposite direction was not. Such findings are supported by the estimated aHR of $1.31 \quad(95 \% \mathrm{CI}=1.14$ to 1.51 ; $\mathrm{p}=0.0001)$ and $1.06(95 \% \mathrm{CI}=0.89$ to $1.25 ; \mathrm{p}=0.5248)$, respectively. Furthermore, there's a significant trend effect of MetS score on FIT-positive result. This result indicates that individuals with metabolic syndrome were more likely to have an elevated risk of being FIT-positive, which further implies an increased risk for colorectal neoplasm. In addition, waist circumference $(\mathrm{aHR}=1.27$, $95 \% \mathrm{CI}=1.13$ to $1.43 ; \mathrm{p}<0.0001$ ), fasting blood glucose ( $\mathrm{aHR}=1.13$, 95\% CI 1.00 to 1.29 ; $\mathrm{p}=0.0547)$, and HDL-C $(\mathrm{aHR}=1.27,95 \% \mathrm{CI}=1.09$ to $1.47 ; \mathrm{p}=0.0019)$ were three significant individual components. These findings are consistent with those reported previous studies that noticed the recognised correlation between MetS components, namely diabetes mellitus, obesity and hypertension and elevated risk of CRC. ${ }^{27-30}$ It has been reported that chronic inflammation plays a pivotal role in complications of obesity, the core condition of MetS, mainly through the inflammatory expansion in adipose tissue. ${ }^{16} 30$

The underlying biological plausibility of our finding is supported by the recent study demonstrating the correlation between glucose level and the adiponectin-adenosine monophosphate-activated protein kinase alpha signalling in the process of colorectal carcinogenesis. ${ }^{31}$ The hypothesised mechanism behind the potential relationship is purported to be through hyperinsulinaemia associated with insulin-like growth factor signalling ${ }^{12} 3233$ or chronic inflammation. ${ }^{34}$ According to Chiu et al, hyperinsulinaemia followed by insulin-resistance might directly activate insulin receptor, IGF-1, which are supposed to play an important role in tumorigenesis of cancers. Low HDL-C is also a characteristic feature of insulin resistance. Similar evidence was noted for the association between low HDL-C and pro-inflammatory cytokines. ${ }^{35}$ Such evidence offers the underlying biological mechanisms accounting for the effect of MetS on incident FIT-positive, namely high $\mathrm{f}-\mathrm{Hb}$, which already demonstrated its predictive role for CRC in a dose-response manner. Thanks to the population-based data with incident cohort study collecting information on both of the two phenotypes, we are able to examine the temporal sequence between both.

The main limitation of this study is related to the generalisability of the results to the external population. Since our target population only included a small fraction of
Taiwanese residents aged 40-79 years and may not be fully representative of the underlying Taiwanese population, external applicability needs to be validated by other eligible population outside the KCIS programme ${ }^{11}$ and even better corroborated by other ethnic groups if possible. The effect of unmeasured confounding factors such as colorectal cancer family history, aspirin intake and the amount of physical activities on the two phenotype is also a possible limitation to our study.

In conclusion, we used bidirectional incident cohort study design to disentangle the temporal relationship of both and found MetS precedes elevated $\mathrm{f}-\mathrm{Hb}$ (incident FIT-positive) but the opposite temporal sequence is unlikely. Given that $\mathrm{f}-\mathrm{Hb}$ have been demonstrated as the early biomarker for subsequent occurrence of colorectal neoplasm, this epidemiological finding may provide empirical evidence-based policy for adopting MetS control over lowering f-Hb concentration for the primary prevention of CRC. However, such an epidemiological association should be verified by using external data in future research.

\section{Author affiliations}

${ }^{1}$ Graduate Institute of Environmental Health, College of PublicHealth, National Taiwan University, Taipei, Taiwan

${ }^{2}$ Department of Health Industry Management, School of Healthcare Management, Kainan University, Taoyuan, Taiwan

${ }^{3}$ Department of Health Care Management, Chang Gung University, Taoyuan, Taiwan ${ }^{4}$ Division of Hepatogastroenterology, Department of Internal Medicine, Chang Gung Memorial Hospital Kaohsiung Branch, Kaohsiung, Taiwan

${ }^{5}$ Graduate Institute of Epidemiology and Preventive Medicine, College of Public Health, National Taiwan University, Taipei, Taiwan

${ }^{6}$ Innovation and Policy Center for Population Health and Sustainable Environment, College of Public Health, National Taiwan University, Taipei, Taiwan

Acknowledgements The authors would like to thank the Public Health Bureau of Keelung City for their contribution and support. This work was financially supported by the 'Innovation and Policy Center for Population Health and Sustainable Environment (Population Health Research Center, PHRC), College of Public Health, National Taiwan University' from The Featured Areas Research Center Program within the framework of the Higher Education Sprout Project by the Ministry of Education (MOE) in Taiwan.

Contributors M-SK and JC-YF contributed equally. SY-HC, H-HC, and C-YH contributed to the conception and design of the work. M-SK, JC-YF and SY-HC contributed to the acquisition, analysis or interpretation of data for the work. M-SK, JC-YF and SY-HC drafted the manuscript. H-HC and C-YH critically revised the manuscript. All gave final approval and agree to be accountable for all aspects of work ensuring integrity and accuracy.

Funding $\mathrm{H}-\mathrm{HC}$ is supported by the Ministry of Science and Technology grant (grant number MOST 107-3017-F-002-003) and The Featured Areas Research Center. Program within the framework of the Higher Education Sprout Project by theMinistry of Education (MOE) in Taiwan (NTU-107L9003).

Competing interests None declared.

Patient consent for publication Not required.

Ethics approval Chang Gung Medical Foundation Institutional Review Board (approval numbers 104-0263C).

Provenance and peer review Not commissioned; externally peer reviewed.

Data sharing statement No additional data are available.

Open access This is an open access article distributed in accordance with the Creative Commons Attribution Non Commercial (CC BY-NC 4.0) license, which permits others to distribute, remix, adapt, build upon this work non-commercially, and license their derivative works on different terms, provided the original work is 
properly cited, appropriate credit is given, any changes made indicated, and the use is non-commercial. See: http://creativecommons.org/licenses/by-nc/4.0/.

\section{REFERENCES}

1. Towler B, Irwig L, Glasziou P, et al. A systematic review of the effects of screening for colorectal cancer using the faecal occult blood test, hemoccult. BMJ 1998;317:559-65.

2. Hewitson P, Glasziou P, Irwig L, et al. Screening for colorectal cancer using the faecal occult blood test, hemoccult. Cochrane Database Syst Rev 2007;1:CD001216.

3. Young GP, Fraser CG, Halloran SP, et al. Guaiac based faecal occult blood testing for colorectal cancer screening: an obsolete strategy? Gut 2012;61:959-60.

4. Ciatto S, Martinelli F, Castiglione G, et al. Association of FOBTassessed faecal $\mathrm{Hb}$ content with colonic lesions detected in the Florence screening programme. Br J Cancer 2007;96:218-21.

5. Chen LS, Yen AM, Chiu SY, et al. Baseline faecal occult blood concentration as a predictor of incident colorectal neoplasia: longitudinal follow-up of a Taiwanese population-based colorectal cancer screening cohort. Lancet Oncol 2011;12:551-8.

6. Chen LS, Yen AM, Fraser CG, et al. Impact of faecal haemoglobin concentration on colorectal cancer mortality and all-cause death. BMJ Open 2013;3:e003740.

7. Yen AM, Chen SL, Chiu SY, et al. A new insight into fecal hemoglobin concentration-dependent predictor for colorectal neoplasia. Int $J$ Cancer 2014;135:1203-12.

8. Digby J, Fraser CG, Carey FA, et al. Faecal haemoglobin concentration is related to severity of colorectal neoplasia. J Clin Pathol 2013:66:415-9.

9. Garcia M, Milà N, Binefa G, et al. Fecal hemoglobin concentration as a measure of risk to tailor colorectal cancer screening: are we there yet? Eur J Cancer Prev 2015;24:321-7.

10. Chen $\mathrm{CH}$, Wen CP, Tsai MK. Fecal immunochemical test for colorectal cancer from a prospective cohort with 513,283 individuals: Providing detailed number needed to scope (NNS) before colonoscopy. Medicine 2016;95:e4414.

11. Chen TH, Chiu YH, Luh DL, et al. Community-based multiple screening model: design, implementation, and analysis of 42,387 participants. Cancer 2004;100:1734-43.

12. Chiu HM, Lin JT, Shun CT, et al. Association of metabolic syndrome with proximal and synchronous colorectal neoplasm. Clin Gastroenterol Hepatol 2007;5:221-9.

13. Kim JH, Lim YJ, Kim YH, et al. Is metabolic syndrome a risk factor for colorectal adenoma? Cancer Epidemiol Biomarkers Prev 2007;16:1543-6.

14. Hu NC, Chen JD, Lin YM, et al. Stepwise relationship between components of metabolic syndrome and risk of colorectal adenoma in a Taiwanese population receiving screening colonoscopy. $J$ Formos Med Assoc 2011;110:100-8.

15. Lumeng CN, Saltiel AR. Inflammatory links between obesity and metabolic disease. J Clin Invest 2011:121:2111-7.

16. Romeo GR, Lee J, Shoelson SE. Metabolic syndrome, insulin resistance, and roles of inflammation-mechanisms and therapeutic targets. Arterioscler Thromb Vasc Biol 2012;32:1771-6.
17. Esser N, Legrand-Poels S, Piette J, et al. Inflammation as a link between obesity, metabolic syndrome and type 2 diabetes. Diabetes Res Clin Pract 2014;105:141-50.

18. Jung UJ, Choi MS. Obesity and its metabolic complications: the role of adipokines and the relationship between obesity, inflammation, insulin resistance, dyslipidemia and nonalcoholic fatty liver disease. Int J Mol Sci 2014;15:6184-223.

19. Terzić J, Grivennikov S, Karin E, et al. Inflammation and colon cancer. Gastroenterology 2010;138:2101-14.

20. Lasry A, Zinger A, Ben-Neriah Y. Inflammatory networks underlying colorectal cancer. Nat Immunol 2016;17:230-40.

21. Barrows GH, Burton RM, Jarrett DD, et al. Immunochemical detection of human blood in feces. Am J Clin Pathol 1978;69:342-6.

22. Alberti KG, Zimmet P, Shaw J. IDF Epidemiology Task Force Consensus Group. The metabolic syndrome--a new worldwide definition. Lancet 2005;366:1059-62.

23. Stocks T, Lukanova A, Bjørge T, et al. Metabolic factors and the risk of colorectal cancer in 580,000 men and women in the metabolic syndrome and cancer project (Me-Can). Cancer 2011;117:2398-407.

24. Jinjuvadia R, Lohia P, Jinjuvadia C, et al. The association between metabolic syndrome and colorectal neoplasm: systemic review and meta-analysis. J Clin Gastroenterol 2013;47:33-44.

25. Tal S, Melzer E, Chsherbakov T, et al. Metabolic syndrome is associated with increased prevalence of advanced colorectal polyps. J Nutr Health Aging 2014;18:22-5.

26. Chiu HM, Lee YC, Tu CH, et al. Effects of metabolic syndrome and findings from baseline colonoscopies on occurrence of colorectal neoplasms. Clin Gastroenterol Hepatol 2015;13:1134-42.

27. Guraya SY. Association of type 2 diabetes mellitus and the risk of colorectal cancer: a meta-analysis and systematic review. World $\mathrm{J}$ Gastroenterol 2015;21:6026-31.

28. Bardou M, Barkun AN, Martel M. Obesity and colorectal cancer. Gut 2013;62:933-47.

29. Amptoulach S, Gross G, Kalaitzakis E. Differential impact of obesity and diabetes mellitus on survival after liver resection for colorectal cancer metastases. J Surg Res 2015;199:378-85.

30. Sell $\mathrm{H}$, Habich $\mathrm{C}$, Eckel J. Adaptive immunity in obesity and insulin resistance. Nat Rev Endocrinol 2012;8:709-16.

31. Vetvik KK, Sonerud T, Lindeberg M, et al. Globular adiponectin and its downstream target genes are up-regulated locally in human colorectal tumors: ex vivo and in vitro studies. Metabolism 2014;63:672-81.

32. Khandwala HM, McCutcheon IE, Flyvbjerg A, et al. The effects of insulin-like growth factors on tumorigenesis and neoplastic growth. Endocr Rev 2000;21:215-44.

33. Cohen DH, LeRoith D. Obesity, type 2 diabetes, and cancer: the insulin and IGF connection. Endocr Relat Cancer 2012;19:F27-F45.

34. Straus DS. TNF $\alpha$ and IL-17 cooperatively stimulate glucose metabolism and growth factor production in human colorectal cancer cells. Mol Cancer 2013;12:78

35. Esteve E, Ricart W, Fernández-Real JM. Dyslipidemia and inflammation: an evolutionary conserved mechanism. Clinical Nutrition 2005;24:16-31. 